\title{
Citizen trust, administrative capacity and administrative burden in Pakistan's immunization program
}

\author{
Sameen A. Mohsin Ali", Samia W. Altaf*
}

\begin{abstract}
Pakistan has the highest infant mortality rate in South Asia, is one of two countries where wild polio is still endemic, and is ranked third for un- or under-immunized children. Why is this the case when considerable donor and government funds have been spent on Pakistan's Expanded Program for Immunization (EPI)? Based on a year of mixed methods research in district Kasur in Punjab, Pakistan, we focus on vaccination as a site of interaction between citizens and the state and apply the concept of administrative burden to explain vaccine hesitancy in Pakistan. As immunization is a non-means tested program where the state approaches citizens expecting full compliance, we argue that learning, psychological, and compliance costs are exacerbated by the context in which parents interact with frontline bureaucrats. Citizens' distrust of an often absent or coercive state and low administrative capacity (specifically overburdened staff, inadequate facilities, and rushed digitization) have a multiplier effect on administrative burdens imposed on parents of young children in accessing immunization programs. Therefore, attempts by the state to vaccinate citizens often exacerbate distrust, and limited capacity hinders the state's ability to reduce the burdens experienced by citizens.
\end{abstract}

Keywords: Administrative burden, immunization, trust, administrative capacity, Pakistan

$\mathrm{M}$ ny countries have been unable to achieve herd immunity for vaccine-preventable diseases (VPD) such s measles, and even countries that have had rigorous immunization programs are now seeing reversals in coverage. The literature studies the characteristics that make refusals more or less likely, for instance, maternal education (Varghese, Kutty, Paina, \& Adam, 2014), religious views (Wombwell, Fangman, Yoder, \& Spero, 2015; Imdad, Tserenpuntsag, Blog, Halsey, Easton, \& Shaw, 2013), and gaps in staff performance (Streefland, 1995) and service provision (Hasan, Bosan, \& Bile, 2010; Karamat, 2004). Though these studies involve an exploration of citizens' understanding (or lack thereof) and perceptions of vaccines, there is less attention paid to immunization as a site of interaction between the state and its citizens, and the context in which this interaction takes place, an exception being sociological work on understanding parental medical choices as involving "priorities, processes, and ambivalences" that require understanding (Reich, 2020, p. 124).

Immunization programs are not means-tested and involve 'bureaucratic encounters' in which the individual initiating the exchange is from a state organization while the recipient is outside that organization-as in the case of the census or voter identification (Heinrich, 2016, p. 2; Kahn, Katz, \& Gutek, 1976). Such encounters turn the process of citizen "claim-making" (Kruks-Wisner, 2019) in developing countries on its head-a state that is typically absent is suddenly present and offering a service free of charge to citizens ${ }^{1}$. These encounters test citizens' trust in the state and reveal its administrative capacity, shaping their perceptions of the costs associated with government policy on vaccination. Though it is acknowledged that both trust and capacity contribute significantly to "the learning, psychological, and compliance costs that citizens experience in their interactions with government", that is, administrative burdens (Herd \& Moynihan, 2018, p. 22), their potential multiplier effects require more attention, particularly since administrative burden literature has focused mostly on welfare programming where the citizen approaches the state (Heinrich, 2016). We investigate the impleme-

\footnotetext{
* Lahore University of Management Sciences

Address correspondence to Sameen A. Mohsin Ali at (sameen.ali@lums.edu.pk)

Copyright: (c) 2021. The authors license this article under the terms of the Creative Commons Attribution 4.0

International License.
} 
ntation of immunization programs in Pakistan, a Low- to Middle-Income Country (LMIC), detailing how distrust in the state, and low administrative capacity exacerbate the learning, psychological, and compliance costs citizens experience in their interactions with state representatives. ${ }^{2}$ Immunization interactions between parents and frontline bureaucrats are shaped by the former's perceptions of the state and its representatives. Based on public beliefs and past experience, many perceive them to be untrustworthy or unreliable. ${ }^{3}$ At the same time, overburdened frontline health workers are unable to take the time to volunteer information or explain to parents what vaccines are for and how they work. Therefore, distrust in the state and low administrative capacity significantly augments administrative burdens on citizens. We summarize these burdens in Table 1, building on the results of a survey and drawing on our interviews with parents and frontline health staff, semi-participant observations at health units and hospitals across Kasur district, insights from the literature on vaccine hesitancy, and the detailing of administrative burdens in the literature on other programs and contexts.

Table 1

Administrative Burden in Immunization Programs in Pakistan

\begin{tabular}{|c|c|c|}
\hline & Distrust of the State & Low Administrative Capacity \\
\hline $\begin{array}{l}\text { Learning } \\
\text { Costs }\end{array}$ & $\begin{array}{l}\text { Costs of locating alternative sources of } \\
\text { information since state representatives do } \\
\text { not answer questions or allay fears } \\
\text { Costs of finding someone to address } \\
\text { specific questions and concerns since } \\
\text { state representatives make it difficult for } \\
\text { citizens to raise them } \\
\text { Unreliable state services require greater } \\
\text { diligence and alternative sources of infor- } \\
\text { mation }\end{array}$ & $\begin{array}{l}\text { Gathering information and paperwork } \\
\text { (particularly vaccination card) for birth } \\
\text { registration } \\
\text { Identifying if a vaccine dose is due } \\
\text { when the vaccinator visits }\end{array}$ \\
\hline $\begin{array}{l}\text { Psychological } \\
\text { Costs }\end{array}$ & $\begin{array}{l}\text { Resentment and fear of the state and } \\
\text { its representatives as a repressive, control- } \\
\text { ling, or extractive entity } \\
\text { Degradation, disempowerment, and } \\
\text { frustration at intrusive, directive, or judg- } \\
\text { mental bureaucratic encounters } \\
\text { Stigma of associating with the state in } \\
\text { accepting vaccination } \\
\text { Stress of greater diligence required to } \\
\text { determine reliability and safety of services } \\
\text { Fear and stress of child falling sick or } \\
\text { dying because of a vaccinee, further ele- } \\
\text { vated through misinformation } \\
\text { Loss of personal autonomy over child's } \\
\text { health }\end{array}$ & $\begin{array}{l}\text { Waiting times and spaces communi- } \\
\text { cating the state's (dis)regard of its citizens } \\
\text { Directive bureaucratic encounter in reg- } \\
\text { istering a birth } \\
\text { Stigma of publicly accessing vaccination } \\
\text { services } \\
\text { Fears of the integrity and efficacy of } \\
\text { vaccines considering capacity constraints } \\
\text { and drug tampering }\end{array}$ \\
\hline $\begin{array}{l}\text { Compliance } \\
\text { Costs }\end{array}$ & $\begin{array}{l}\text { Costs of having to take time off work if } \\
\text { child gets a fever from the vaccine } \\
\text { Costs of seeking private health care }\end{array}$ & $\begin{array}{l}\text { Costs of a visit to the health facility if a } \\
\text { child is born at home } \\
\text { Costs of registering a birth } \\
\text { Taking the time to take the child to the } \\
\text { vaccinator camp } \\
\text { Taking time off to take the child to a } \\
\text { health facility for a missed vaccination }\end{array}$ \\
\hline
\end{tabular}




\section{Context and Methodology}

Pakistan is ranked third for having the most un- or under-immunized children in the world. ${ }^{4}$ The infant mortality rate is 69 per 1000 births — the highest in South Asia. ${ }^{5}$ Despite considerable funding from international donors for Pakistan's Expanded Program for Immunization (EPI), vaccine preventable diseases persist, including polio. Vaccination rates vary considerably by region, revealing the impact of societal inequalities, particularly gender, wealth, and mother's education, on coverage (Imran, Raja, Grassly, Wadood, Safdar, \& O'Reilly, 2018; Khan \& Khan, 2012). The reasons posited for poor vaccination coverage in Pakistan include corruption, religious beliefs, unplanned devolution, lack of awareness, and poor access to services (Haq, Shaikh, Tran, Hafeez, \& Ghaffar, 2019; Haque, Waheed, Masud, Malick, Yunus, Rekhi, Oelrichs, \& Kucheryavenko, 2016; Khowaja et al., 2012; Owais et al., 2011; Hassan et al., 2010; Karamat, 2004; Interview 1).

This article draws on mixed methods research conducted over a year in the district of Kasur in the province of Punjab, Pakistan. ${ }^{6}$ Kasur district borders the provincial capital of Lahore and is relatively well supplied in terms of infrastructure and services, allowing us to gauge what issues in public health service provision persist despite urbanization and higher levels of development. Our research involved an exploratory survey and qualitative fieldwork (semi-participant observations and interviews) designed to understand issues in the supply and demand of immunization services. The survey was not designed to infer causal relationships; rather, its purpose was to develop an evidence base for further fieldwork.

We surveyed 179 households across the district of Kasur using the WHO's Seven Cluster Method (Appendix A and B) and relied on data from the Pakistan Social and Living Standard Measurement (PSLM) Surveys 2012-13 and 2014-15. To provide context and to triangulate our survey findings, we visited major government hospitals, and some Basic Health Units (BHUs), and Rural Health Centres (RHCs) across the district, and interviewed provincial and district health bureaucrats (including vaccinators, doctors, and lady health workers). Our interviews were based on convenience sampling and in total we interviewed 20 people (Appendix D). A more detailed account of our fieldwork is provided in Appendix A.

\section{Learning, Psychological and Compliance Costs: State Neglect and Citizen Trust}

The importance of trust in the state and in the equity and fairness of its processes and outcomes is widely accepted (Van Ryzin, 2011); writing about the US, Moynihan, Herd, \& Rigby (2016) note that adverse experiences with the state can lead to reduced "civic participation and political engagement". Vaccination is based on interpersonal contact between a vaccinator and a child's parents and involves notions of parental responsibility. Unlike antibiotics or other medication, vaccines are administered when the child is not presenting with any symptoms. Therefore, significant learning, compliance, and psychological costs are imposed as parents try to gather information about government provision and best practices. The consequence is vaccine hesitancysuspicion or even outright fear of vaccination - which can persist alongside trust in and use of other medication like antibiotics (Reich, 2020).

Since encounters with the state can often be seen as 'intrusive' and as reducing levels of 'civic and political trust' (Keiser \& Miller, 2020, 138; Kumlin, 2004), officials' attitudes can be very important to how receptive parents are to vaccination. Frontline bureaucratic encounters form the basis of an extensive literature on a variety of welfare programs (Kahn etal., 1976; Lipsky, 1980; Wolfe \& Srivner, 2005; Brodkin \& Majmundar, 2010; Soss, Fording, \& Schram, 2011; Barnes \& Henly, 2018). Though immunization programs do not allow bureaucrats the kind of powers they might have in means-tested welfare programs, bureaucrats can control what information or assistance they offer to citizens (Moynihan et al., 2016) and can and do make judgements about parents' priorities and care for their child. Furthermore, the perceived imposition of vaccines is in stark contrast to the state's usual absence or unsatisfactory performance in developing countries, causing resentment and fear of vaccines as a means for the government to control or extract from the population. For instance, some of our respondents feared that the government would impose new taxes based on the number of children they had. In some communities, vaccines are considered a conspiracy to render the population of Muslim nations sterile or are regarded as 'religiously forbidden' (Khowaja et al., 2012, p.826). More recently in Pakistan, 
vaccination programs have been tainted as a consequence of their association with a US spy (Martinez-Bravo \& Stegmann, 2020; Hussain, Boyle, Patel, \& Sullivan, 2016).

In the former Federally Administered Tribal Areas (FATA) in the northwest of Pakistan, for example, people perceive the government as caring only about polio and none of their other needs. As in other countries like Nigeria and India (Grossman, Phillips, \& Rosenzweig, 2017, p.3), they use the polio vaccination as a bargaining chip with the state, refusing to vaccinate their children until their specific demands are met-from claims for displacement compensation to enforcement of land rights (Khan, 2019; Hashim, 2019). Grossman, Phillips, and Rosenzweig (2017) find that the Nigerian state began to pre-empt such demands to guarantee polio vaccinations. Pakistan has so far not been able to achieve this, likely due to a lack of political consensus on eradicating polio and an unwillingness to adapt new strategies (International Monitoring Board for Polio Eradication 2019, p.13). Citizens living in militarized border regions such as former FATA perceive the state in a manner that imposes its own psychological costs. The Pakistani state has had a history of engaging in human rights abuses and repression through colonial era laws in FATA (International Crisis Group Briefing No. 150). Citizens' experiences of discrimination and injustice at the hands of the state stigmatize any further dealings with that state and its representatives (Independent Monitoring Board of the Global Polio Eradication Initiative 2019, p.14), raising psychological costs for citizens in engaging with vaccination programs. Furthermore, since the state is seen as untrustworthy and unapproachable, the most readily available avenue for information on vaccinations in an underserved region becomes inaccessible, increasing both learning and compliance costs for citizens.

Even where the state is present-in the political heartland of Punjab, where Kasur is located-it can be difficult to get citizens to trust state services, even when provided free of charge and at their doorstep. Citizens often have valid concerns regarding the uncertainty and safety of state service provision, emerging, for example, from media reports of fake medications causing the death of patients in government hospitals (WHO 2013; Interviews 7 and 10). Such concerns drive up learning costs as citizens must be more diligent and seek alternative sources of information, and psychological costs as citizens experience the stress of ensuring the health and safety of their children in their interactions with the state. Stress as a consequence of government interactions is under researched (Moynihan, Herd, \& Harvey, 2015, p.50), but it is a critical element of the interaction between the state and the parent over immunization. Concerns over quality of provision are evident in the experiences of Kasur's District Superintendent Vaccinations (DSV), who began his career as a vaccinator, with parents (Interview 5):

[We explain to parents] that this vaccine is good for your children, it is beneficial. But they say that they will go to [a private hospital in the neighbouring provincial capital Lahore] because their vaccines are better than those that the vaccinator has [because the private hospital charges] Rs 40,000 [approximately USD 250] for it. ... Some people will refuse to be vaccinated by vaccinators visiting their homes, they say that the vaccine at the [government run] Rural Health Centre is better.

Parental preference for government health facilities or private health care might be the result of an unwillingness to engage with government workers. Frontline health staff, such as vaccinators, can make vaccination a fraught process for parents by being 'directive' and making parents feel that they do not have 'the capacity to determine how to live their lives' (Moynihan et al., 2015, p.49-50). In some cases, frontline staff are impatient when parents resist vaccination, as one of our survey respondents did, by claiming that, "The children fall sick and cry a lot after the vaccination". For instance, Kasur DSV's spoke of his frustrations with parents (Interview 5):

In some rural areas, uneducated people care more for themselves than for their children. [They care about] eating and drinking. Whether the children are vaccinated or not, never mind.

Judgemental comments of this nature regarding parenting decisions and styles, and the use of force to vaccinate children, are likely to turn parents against government workers and services (Reich, 2020). There are, of course, biases involved in such attitudes; wealthier parents are more likely to be treated with respect by health service providers (Reich, 2020; Gengler, 2014). Therefore, administrative burdens reinforce societal inequalities 
(Herd \& Moynihan, 2018), reveal 'how marginalization is experienced and (re)produced' (Nisar, 2017, p. 3), and both contribute to and are shaped by levels of trust in the state.

Christensen, et al. (2020) explain that officials interpret 'low executive functioning' as the person being lazy or unmotivated, and therefore, undeserving (Aaroe \& Petersen, 2014; Hansen, 2018; Jilke \& Tummers, 2018). Even otherwise, bureaucratic experiences impose psychological costs because they can be "disempowering" (Moynihan et al., 2015, p.50) or even "degrading, intrusive, and directive" (Moynihan et al., 2015, p.49). Such experiences also raise learning and compliance costs since citizens find it difficult to ask questions or raise their concerns with officials. Most of our survey respondents claimed that the vaccinator did not explain the need for the vaccine being administered to a child (Figure 1) and complained that vaccinators did not explain how vaccines would help or how they work: ${ }^{7}$

"They don't guide us, nor they do give any details about the purpose and effectiveness of the vaccines."

"They only tell us about polio and measles, they've never elaborated on the benefits of the vaccines."

"The teams don't tell us about the benefits of the vaccines."

"They did not tell us about why vaccines are important."

"They inform us of only the repercussions of not getting the child vaccinated for polio, they don't give us proper details about the whole process and why it is important. The information we have is through television, the Lady Health Worker doesn't provide us with the full details."

"They only announce the arrival of the [vaccination] teams, they do not give us information."

Figure 1

Did the Vaccinator Explain Why the Vaccine was Needed?

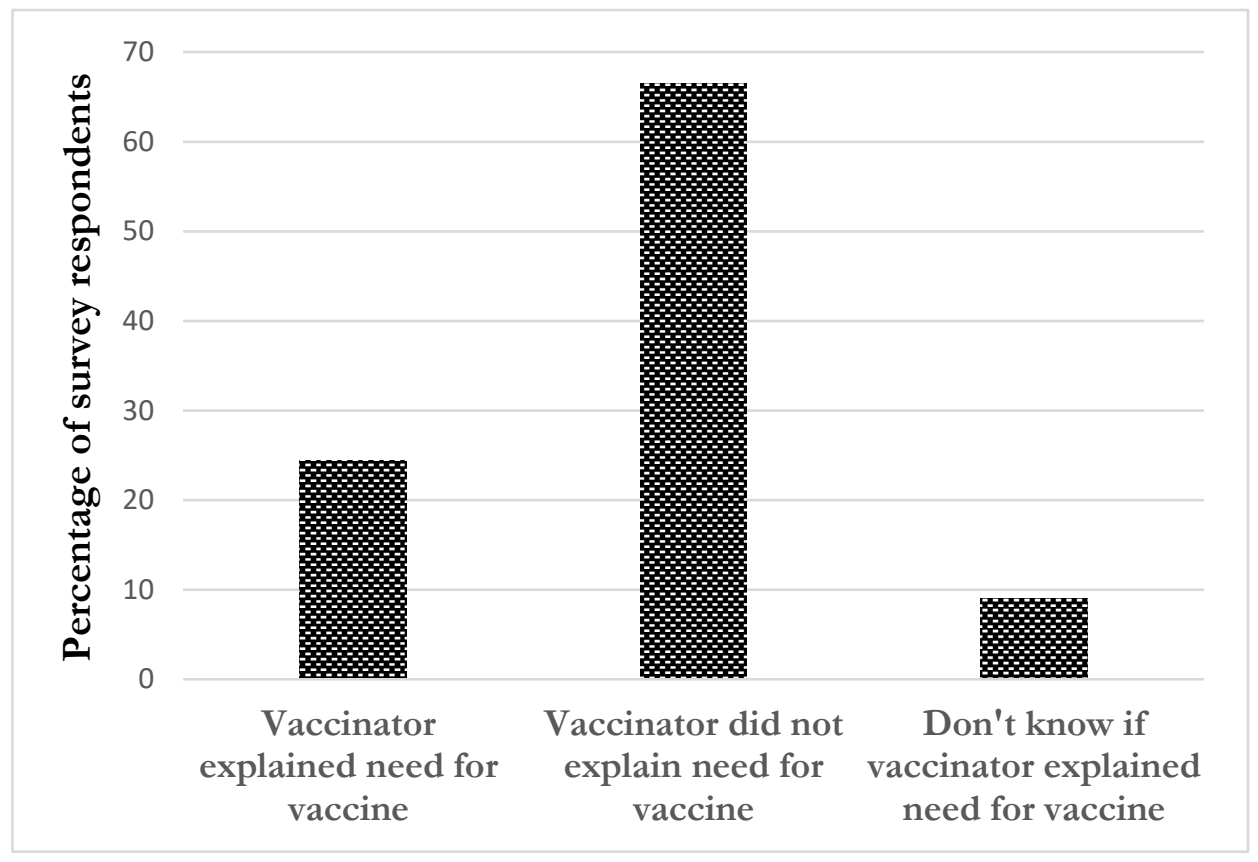

Learning and psychological costs become even more problematic when parents are unaware of the side effects of vaccines. Fear for their children's wellbeing - in part the consequence of high learning costs and the absence of information - discourages parents from vaccinating their children. Of our 179 respondents, 63\% were unaware of any side effects of vaccines. These parents misinterpret common side effects such as fever or muscular pain as a disease caused by the vaccine (Interview 12). Not only does this lead to significant stress and 
worry, causing greater distrust in state provision of services, but to material costs of compliance for parents as well, further incentivizing vaccine refusals. The Kasur DSV explained (Interview 5):

"Sometimes, the mother tells us that if I get the child vaccinated, they will get a fever. I will not be able to work. [Especially in villages near the river] many women work on daily wages."

These costs also make parents more fearful and susceptible to misinformation that frontline health workers are ill-equipped to counter (Jamal, Zaidi, Husain, Orr, Riaz, Farrukhi, \& Najmi, 2020; Bhattacharjee \& Dotto, 2020), further impacting trust in the state. Fear closely shadows immunization campaigns in Pakistan. Two mothers explained why they refused vaccines for their children even when provided free of cost:

"She had fever for three days after she got the injections, normally the fever lasts only a few hours after the injection. Her fever lasted three days, so we didn't get her vaccinated the next time."

"I went to my mother's house and there an infant died right after she got vaccinated. When I came back to my own house and the team arrived for vaccination, I refused to get my daughter vaccinated due to the fear that that would happen."

The Pakistani state's response to polio vaccine refusals was, till quite recently, to arrest the parents (Hussain, Menezes, \& Nagaraja, 2015; Junaidi, 2019). Such policies are perceived by parents as a loss of personal autonomy and the imposition of the state's might on matters related to the health and wellbeing of their children, for whom they are ultimately responsible (Reich, 2020; Hattke, Hensel, \& Kalucza, 2020; Yusufzai, 2015). Therefore, such strong-arm tactics fail to get a sustainable commitment to vaccination from the parent, who begins to associate immunization with the use of force by the state (Interview 1).

Arguably, including vaccinations as part of hospital births and nutritional assessments might mean that parents would be less opposed to vaccines being administered by reducing the impression that immunization is unique as the one task for which the state chases after its citizens. Currie and Gruber (1996) make a similar argument: reduced learning, psychological, and compliance costs are the reason that those enrolled in one government program are more likely to take advantage of other services as well. However, in Kasur at least, statistics on government services uptake, where a citizen must interact with a state representative (staff at government hospitals or Lady Health Workers or Visitors [LHWs and LHVs]), are worrying. Figure 2 shows a growing reliance on private health care, and Figure 3 a decline in government hospital births, with a commensurate increase in home births in Kasur between 2012-13 and 2014-15. Explanations for such trends are complex but they suggest that government health services are poorly managed in the district, feeding into the growth of, and increasing reliance on, private healthcare facilities.

Figure 2

\section{Percentage of Pre-natal \& Post-natal Consultations by Service Type 2012-13 \& 2014-15}

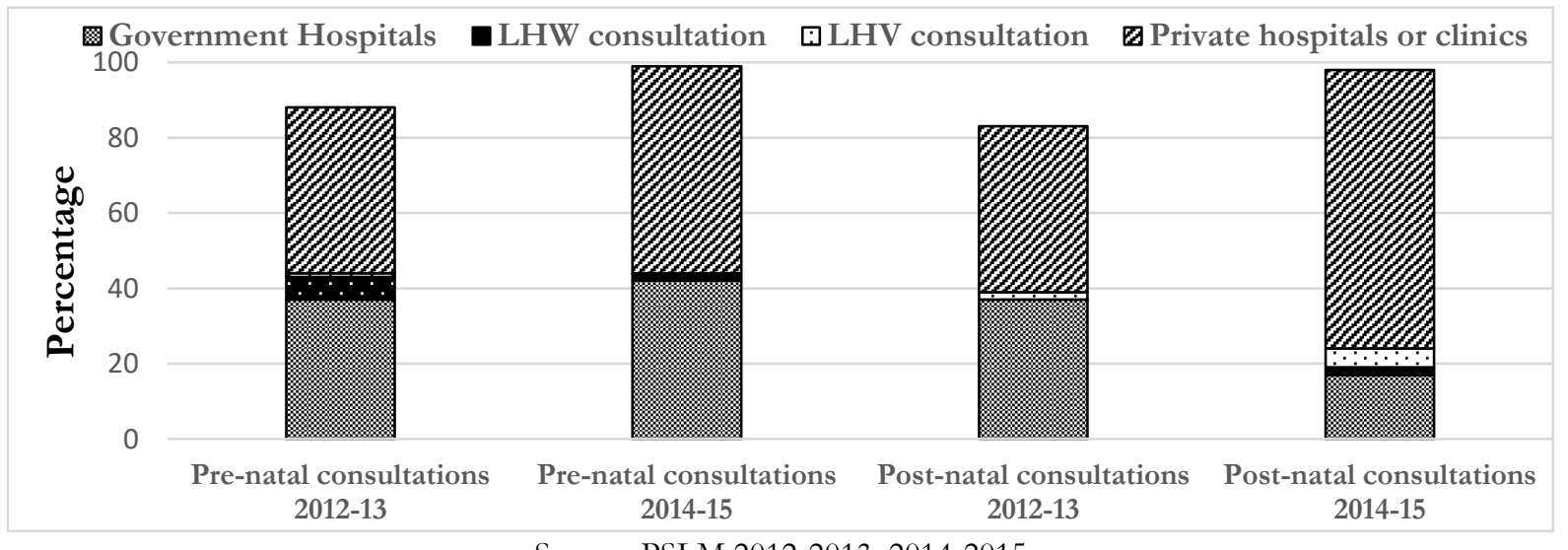

Source: PSLM 2012-2013; 2014-2015 
Figure 3

Percentage of Births by Type of Facility, 2012-2013 \& 2014-2015

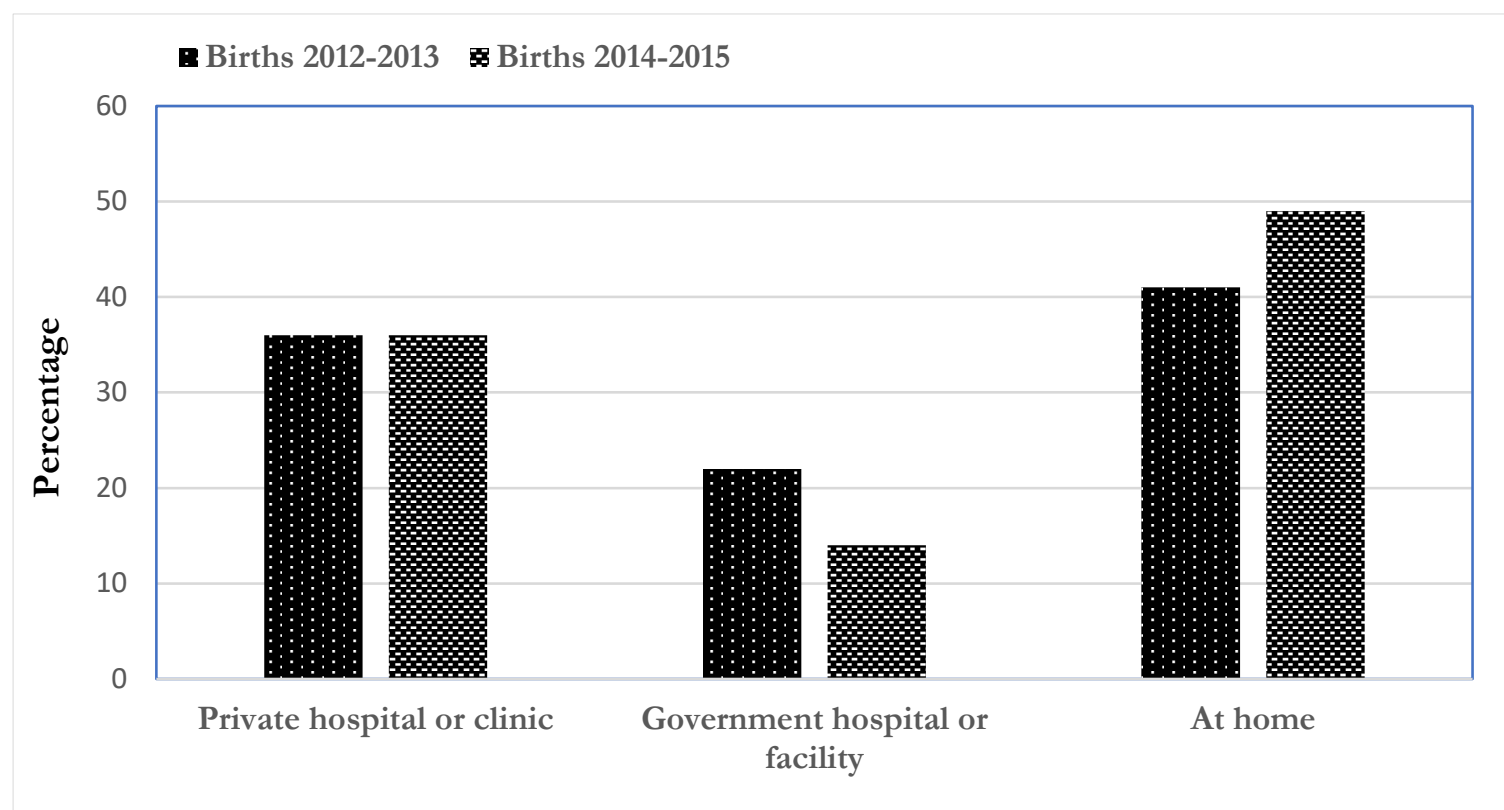

Source: PSLM 2012-2013; 2014-2015

\section{Learning, Compliance and Psychological Costs, and Administrative Capacity}

Parents are expected to have an up-to-date, government issued vaccination card for each child and to follow the vaccination schedule mentioned on it. This card is necessary to register a birth and an essential part of the process of citizenship in Pakistan. Though the requirement imposes the compliance, learning, and psychological costs of an additional bureaucratic process, this relatively small intervention is regarded by bureaucrats at the provincial and district levels as having had a significant positive impact on vaccination coverage (Interviews 1, 5 , and 13). The compliance cost is higher for parents of children who are born at home for they do not have a vaccination card unless a health worker visits, or they go to the nearest health facility.

Health facility visits involve psychological costs. Studies suggest waiting times and spaces, and spatial distinctions between citizens and state representatives may be "communicating the limited standing of the claimant" (Moynihan et al., 2015, p.50). This is a significant issue in Pakistan where there are 10 medical doctors, 6 nurses and midwifery personnel, and 6 hospital beds per 10,000 people. ${ }^{8}$ Health facilities are overwhelmed (Interview 10) and parents can spend hours waiting to speak to a doctor only to receive a rushed consultation.

Issues of capacity and quality control further exacerbate parents' fears regarding the effects, efficacy, and integrity of vaccines provided by the state, making them suspicious of frontline bureaucrats and imposing further psychological costs that define their experience as citizens. Cold chain maintenance was a pressing concern since vaccines are carried in cold boxes from one village to another at the height of the summer (Interview 10, 15 , and 16). With chronic electricity and diesel shortages, staff take vaccines home to store in their freezers in blocks of ice (Interview 10 and 12). Such practices can compromise the potency of the vaccine and cause the label to peel off, leaving vaccinators with little means of determining the vial's contents (Interview 10).

In immunization programs where the state must reach out to its citizens, compliance must be ensured by frontline government workers, primarily through monitoring and reporting requirements that form the basis of coverage statistics (Weaver, 2014). Ensuring such compliance is complicated by inadequate staffing, deficient facilities, and poorly planned digitization. These indicators of poor administrative capacity multiply the work- 
load of bureaucrats which, in turn, increases learning, compliance, and psychological costs for citizens. In Punjab, vaccination programs are understaffed at the district level (Interview 1, 5, and 7). For Kasur, the DSV counts 112 Union Councils (UCs, the smallest administrative unit) ${ }^{9}$ with 99 working vaccinators and 13 seats vacant due to a shortage of funds for recruitment, compensated for by training other staff, such as LHWs and LHVs, to fill the gap (UNICEF 2019; Interview 5). But, even in UCs where a vaccinator is employed, the task before them is monumental. Between 1998 and 2017, the population of Kasur grew by 2\% to 3,454,996. Therefore, the population per UC has grown to between 25,000 and 30,000. As of 2017, following delimitation, there are now 125 union councils in Kasur district. ${ }^{10}$ However, operationally, immunization staff referred to 112 UCs as service delivery and appointments had not yet been re-structured (Interview 4, 5, and 9). One vaccinator is simply not enough to cover all eligible children, particularly considering their low wages, poor training, the contractual nature of their employment, and the government not paying fuel costs for their transport (Interview 5,15 , and 16).

Consequently, vaccinators and LHWs do not have the time to answer parents' questions or allay their fears, leaving them fearful and frustrated. Vaccinators visiting a community set up camp at a central point and announce their presence via the local mosque. Learning and compliance costs shift to the parent-if a vaccine dose is due, they must take the child to the vaccinator's camp, which may carry psychological costs as accessing vaccinations becomes a public exercise. In villages where prominent citizens, such as the local religious leader, refuse vaccinations, publicly accessing them might carry stigma and psychological costs. If a child misses a vaccine dose on that day, the compliance cost is again on the parent who must take time off work to visit the nearest health facility, which brings attendant psychological costs of long waiting times and rushed consultation.

Digital dashboards have only added to the vaccinator's work, meaning longer waiting times and thus higher psychological costs for citizens. In 2012, the Punjab government introduced an attendance monitoring system for vaccinators' attendance and digital entry of the details of each child immunized. Already overburdened vaccinators, LHWs, and LHVs now feel additional pressure to ensure that they meet set targets for children immunized, which incentivizes false entries (Interview 4 and 5) and provides little incentive to educate citizens or alleviate their fears. Furthermore, unfamiliar with digital systems, vaccinators and staff at government health centres first enter the details of immunized children in a register and then later feed it into the computer, effectively doubling their work (Interviews 10 and 11).

\section{Conclusion}

This study of citizen-state interactions in vaccination programs finds that the state's administrative capacity and citizens' trust in the state can produce a multiplier effect on learning, psychological, and compliance costs experienced by citizens. Especially in interactions initiated by the state itself with the expectation of full compliance (as in the case of vaccination), context, prior experience, and citizen trust are crucial factors that determine engagement and uptake. However, even if there is a recognition of costs to the citizen on the part of state representatives, low levels of trust and capacity hinder both the will and ability of the state to reduce these costs. Therefore, parents face greater stress and expense, especially those lacking the requisite human capital to deal with burdens (Christensen et al., 2020), potentially leading to a further decline in trust.

An implication of the multiplier effect we outline is the suggestion that services are bundled togetherfor example, maternal health services with childhood vaccinations-to reach more citizens through trusted channels while requiring relatively little additional investment by the state. But such an approach runs the risk of overburdening existing staff, increasing costs for citizens, and driving them to private healthcare that they can ill afford. In LMICs in particular, therefore, the state must first recognize the imposition of burdens, understand their effects, particularly on the vulnerable and marginalized (e.g., Heinrich 2016 on South Africa; Nisar 2017 on Pakistan), and eventually, as Moynihan, Herd, and Harvey $(2015,65)$ argue, develop a contextualized policy response to equip the state to take on these burdens. Monitoring service delivery and compliance through rushed digitization is, however, an instance of putting the cart before the horse: it overlooks the citizen experience and, in the absence of significant investment in the sector, adds to the workload of frontline bureaucrats, further exacerbating costs for citizens—as Soss, Fording, and Schram (2011) find in welfare programming. 
Fundamentally, reducing administrative burdens requires care, forethought, and investment (fiscal and otherwise) by the state — an inherently political project, as Herd and Moynihan (2018) contend. A limitation of our study is that we do not address Pakistan's political or policy debates on health or immunization in any detail. Furthermore, our research focuses on Pakistan's most developed province, and with a limited sample. Nonetheless, this article connects micro and macro approaches in public administration (Moynihan 2018, 4) using a citizen-centric, contextualized approach to assess the impact of state capacity and trust on the challenges faced in accessing public services. We encourage scholars and practitioners to study the particularities of citizen-state encounters in LMICs by adapting the administrative burdens framework, especially the politics of establishing burdens, regional variations in burdens, and marginalized communities' experiences in means tested and nonmeans tested programs.

\section{Notes}

1. The literature on compliance (see, for example, Weaver, 2014) is complementary in many ways to the administrative burden framework. However, we found the latter better suited to accounting for learning and psychological costs for citizens, particularly in programs where the state approaches the citizen and not the other way around.

2. We prefer to think of these costs as imposed on citizens through policy choices made by governments (Herd \& Moynihan, 2018, p. 31; Herd \& Moynihan, 2020), rather than problems to be dealt with to ensure compliance (Weaver, 2014). However, departing from Herd and Moynihan's (2018) main argument of burdens as politics by other means, we do not engage with policy making or politics regarding Pakistan's immunization program in this paper. This is not to say that politics is absent from policy making or implementation of immunization programs, quite the contrary.

3. See, for example, Acemoglu, et al. (2019) on distrust in state institutions in Pakistan.

4. WHO Pakistan-Expanded Program on Immunization http://www.emro.who.int/pak/programmes/expanded-programme-on-immunization.html

5. UNICEF Pakistan Country Profile https://data.unicef.org/country/pak/

6. Lahore University of Management Sciences IRB /09152018

7. See Appendix $C$ for the considerable variation in people's understanding of vaccines, and Jamal, et al. (2020) on vaccination rates in Sindh, Pakistan and Iyal, et al. (2018) on unmet needs regarding polio vaccination in Nigeria's Kaduna state.

8. WHO's Pakistan statistics summary https://apps.who.int/gho/data/node.country.country-PAK; Global Health Observatory https://apps.who.int/gho/data/?theme=main

9. There were actually 113 UCs in Kasur prior to recent delimitation, as per Punjab Development Statistics 2013 http://www.bos.gop.pk/system/files/Dev-2013.pdf

10. Notification, Local Government and Community Development Department, Punjab. https://lgcd.punjab.gov.pk/system/files/UCDCKasur.pdf

\section{Acknowledgments}

This research is funded by the Shahid Hussain Foundation, and we are thankful to Uzma Hussain Hayat and Dr Kamran Asdar Ali for their enthusiastic support of this project. We are grateful to three anonymous reviewers and the JBPA editors for valuable comments that helped improve this paper. We are thankful to the Technology for People Initiative for their support, particularly Dr Fareed Zaffar and Fatima Bilquis, and for the able research assistance of Rohail Asim, Jazib Parvez, Azka Shahid, Bismah Azhar, and Yahya Aftab, and for the energy and input of our enumerators Muddsar Akhter, Benish Rashid, Aimen Afzal, Humaira Naz, Kalsom Aziz, Muhammad Imran, Nighat Iqbal, Salman Shafiq, and Abu Sufiyan. Most of all, we are grateful to all our respondents for sharing their experiences with us. 


\section{References}

Aarøe, L. \& Petersen, M. B. (2014). Crowding out culture: Scandinavians and Americans agree on social welfare in the face of deservingness cues. Journal of Politics, 76(3), 684-697.

https://doi.org/10.1017/S002238161400019X

Acemoglu, D., Cheema, A., Khwaja, A. I., \& Robinson, J. A. (2019). Trust in state and nonstate actors: Evidence from dispute resolution in pakistan. Journal of Political Economy, 128:8, 3090-3147. https://doi.org/10.1086/707765

Barnes, C.Y. \& Henly, J. R.. (2018). “They are underpaid and understaffed": How clients interpret encounters with street-level bureaucrats. Journal of Public Administration Research and Theory, 28(2), 165-181, https://doi.org/10.1093/jopart/muv008

Bhattacharjee, S. \& Dotto, C. (2020). Understanding the impact of polio vaccine disinformation in Pakistan. First Draft Case Study, First Draft News. https:// firstdraftnews.org/long-form-article/ first-draft-casestudy-understanding-the-impact-of-polio-vaccinedisinformation-in-pakistan/

Brodkin, E. Z., \& Majmundar, M. (2010). Administrative exclusion: Organizations and the hidden costs of welfare claiming. Journal of Public Administration Research and Theory, 20, 827-48. https://doi.org/10.1093/jopart/mup046

Christensen, J., Aarøe, L., Baekgaard, M., Herd, P. \& Moynihan, D. (2020). Human capital and administrative burden: The role of cognitive resources in citizen-state interactions. Public Administration Review, 80(1), 127-136.

https://doi.org/10.1111/puar.13134

Currie, J., \& Gruber, J. (1996). Health insurance eligibility, utilization of medical care, and child health. Quarterly Journal of Economics, 111, 431-66. https://doi.org/10.2307/2946684

Expanded Program on Immunization, Pakistan. Comprehensive Multi-Year Plan, 2014- 2018. http://epi.gov.pk/wp-content/uploads/2014/09/national-cmyp.pdf

Gengler, A. M. (2014). 'I want you to save my kid!' Illness management strategies, access, and inequality at an elite university research hospital. Journal of Health and Social Behavior, 55(3), 342-359. DOI: 10.1177/0022146514544172

Grossman, S., Phillips, J. \& Rosenzweig, L. R. (2017). Opportunistic accountability: State-society bargaining over shared interests. Comparative Political Studies, $51(8)$ 979-1011. https://doi.org/10.1177/0010414017720706

Hansen, K.J. (2018). Perceptions of rich and poor people's efforts and public opinion about economic redistribution. PhD diss., Aarhus University. http://politica.dk/fileadmin/politica/Dokumenter/ph.d.afhandlinger/kristina jessen.pdf
Haq, Z., Shaikh, B. T., Tran, N., Hafeez, A. \& Ghaffar, A. (2019). System within systems: Challenges and opportunities for the Expanded Programme on Immunisation in Pakistan. Health Research Policy and Systems, 17(51). https://doi.org/10.1186/s12961-0190452-Z

Haque, M. U.; Waheed, M.; Masud, T.; Malick, W. S.; Yunus, H.; Rekhi, R.; Oelrichs, R.; \& Kucheryavenko, O. (2016). The pakistan expanded program on immunization and the national immunization support project: An economic analysis. Health, Nutrition and Population Discussion Paper; Washington, DC: World Bank. https://openknowledge.worldbank.org/ handle/10986/25864

Hasan, Q., Bosan, A.H. \& Bile, K.M. (2010). A review of EPI progress in Pakistan towards achieving coverage targets: present situation and the way forward. EMHJ - Eastern Mediterranean Health Journal, 16 (Supp.), 31-38.

Hashim, A. 2019. In Pakistan, polio makes a comeback amid vaccine boycotts. Al Jazeera, 29 December. https://www.aljazeera.com/features/2019/12/29/in-pakistan-polio-makes-acomeback-amid-vaccine-boycotts

Hattke, F., Hensel, D., \& Kalucza, J. (2020). Emotional responses to bureaucratic red tape. Public Administration Review, 80(1), 53-63. https://doi.org/10.1111/puar.13116

Heinrich, C.J. (2016). The bite of administrative burden: A theoretical and empirical investigation. Journal of Public Administration Research and Theory, 26(3), 403-420, https://doi.org/10.1093/jopart/muv034

Herd, P. \& Moynihan, D. P. (2018). Administrative burden: Policymaking by other means. New York: Russell Sage Foundation.

Herd, P. \& Moynihan, D. P. (2020). How administrative burdens can harm health. Health Affairs Health Policy Brief, October. DOI: 10.1377/hpb20200904.405159

Hussain, S. A., Menezes, R. G., \& Nagaraja, S. B. (2015). Parents in Pakistan arrested for polio vaccine refusal: A necessary step? The Lancet, Correspondence, 285(9977), P1509. https://doi.org/10.1016/S01406736(15)60751-6

Hussain, S.F., Boyle, P., Patel, P., \& Sullivan, R. (2016). Eradicating polio in Pakistan: An analysis of the challenges and solutions to this security and health issue. Globalization and Health, 12(63). DOI 10.1186/s12992-016-0195-3.

Imdad, A., Tserenpuntsag B., Blog, D. S., Halsey, N.A., Easton, D. E., \& Shaw, J. (2013). Religious exemptions for immunization and risk of pertussis in New York State, 2000-2011. Pediatrics, 132(1), 37-43. DOI: $10.1542 /$ peds.2012-3449 
Imran, H.; Raja, D.; Grassly, N. C.; Wadood, M. Z.; Safdar, R. M.; \& O’Reilly, K. M. (2018). Routine immunization in Pakistan: Comparison of multiple data sources and identification of factors associated with vaccination, International Health, 10(2), 84-91, https://doi.org/10.1093/inthealth/ihx067

Independent Monitoring Board. (2019). The art of survival: The polio virus continues to exploit human frailties. The Global Polio Eradication Initiative Report. https://reliefweb.int/sites/reliefweb.int/ files/resources/17th-IMB-report-20191115.pdf

International Crisis Group. (2018). Shaping a new peace in Pakistan's tribal areas. Briefing No. 150, 20 August. https://www.crisisgroup.org/asia/south-asia/pakistan/b150-shaping-new-peace-pakistans-tribal-areas

Interview 1 (2018). Director General Expanded Program for Immunization (EPI) Punjab, 16 October and 20 November 2018.

Interview 4 (2018). Vaccinator, Kasur, 13 December 2018 Interview 5 (2019). District Superintendent Vaccinations, Kasur, 13 December 2018 and 17 January 2019

Interview 7 (2018). Medical Superintendent, Kasur District Headquarter Hospital, 13 December.

Interview 9 (2019). Trainers (2), Kasur Vaccination Program, 17 January.

Interview 10 (2019). Medical officers (2), Rural Health Centre, Kasur 9 March.

Interview 11 (2019). Lady Health Visitor, Rural Health Centre, Kasur 9 March.

Interview 12 (2019). Lady Health Worker, Kasur, 18 March.

Interview 13 (2019. Secretary Union Council Kasur, 20 March.

Interview 15 (2019). Supervising Vaccinator, Kasur, 12 October.

Interview 16 (2019). Vaccinator, Kasur, 12 October.

Iyal, H.A., Shuaib, F., Dauda, M. et al. (2018). Assessment of unmet needs to address noncompliant households during polio supplemental immunization activities in Kaduna state, 2014-2016. BMC Public Health 18:1309. https://doi.org/10.1186/s12889-0186192-0

Jamal, D., Zaidi, S., Husain, S., Orr, D. W., Riaz, A., Farrukhi, A. A., \& Najmi, R. (2020). Low vaccination in rural Sindh, Pakistan: A case of refusal, ignorance or access? Vaccine, 38:30, 4747-4754. https://doi.org/10.1016/j.vaccine.2020.05.018

Jilke, S. \& Tummers, L. (2018). Which clients are deserving of help? A theoretical model and experimental test. Journal of Public Administration Research and Theory, 28(2), 226-238.

Junaidi, I. (2019). Parents refusing polio vaccination will not face police cases. DAWN, June 17. https://www.dawn.com/news/1488676

Kahn, R.L., Katz, D., \& Gutek, B. (1976). Bureaucratic encounters - an evaluation of government services. The Journal of Applied Behavioral Science, 12, 178-198.
Karamat K. A. (2004). Vaccine security in Pakistan. Working paper 01-Health. Planning Commission of Pakistan, Islamabad.

Keiser, L. R., \& Miller, S. M. (2020). Does administrative burden influence public support for government programs? Evidence from a survey experiment. Public Administration Review, 80(1), 137-150. DOI: $10.1111 /$ puar. 13133

Khan, A. \& Khan, A. (2012). Childhood immunization in Pakistan. USAID Research and Development Solutions, Policy Brief Series No. 3, February 2012. http://resdev.org/files/policy brief/3/3.pdf

Khan, A. (2019). Polio: What's behind the refusals? $D A W N$, September 29. https://www.dawn.com/news/1507831/poliowhats-behind-the-refusals

Khowaja, A. R., Khan, S. A., Nizam, N., Omer, S. B., \& Zaidi, A. (2012). Parental perceptions surrounding polio and self-reported non-participation in polio supplementary immunization activities in Karachi, Pakistan: A mixed methods study. Bulletin of the World Health Organization, 90(11), 822-30. DOI: 10.2471/BLT.12.106260

Kruks-Wisner, G. (2019). Claiming the state: Active citizenship and social welfare in rural India. New York: Cambridge University Press.

Kumlin, S. (2004). The personal and the political: How personal welfare state experiences affect political trust and ideology. Basingstoke: Palgrave Macmillan.

Lipsky, M. (1980). Street-level bureaucrats. New York: Russell Sage Foundation.

Martinez-Bravo, M. \& Stegmann, A. (2020). In vaccines we trust? The effects of the CIA's vaccine ruse on immunization in Pakistan. Working Paper. https://www.cemfi.es/ martinez-bravo/mmb/Research files/MS Vaccines 20200814.pdf $\mathrm{n}$

Moynihan, D. (2018). A great schism approaching? Towards a micro and macro public administration. Journal of Behavioural Public Administration, 1(1), 1-8. https://doi.org/10.30636/jbpa.11.15

Moynihan, D., Herd, P., \& Harvey, H. (2015). Administrative burden: Learning, psychological, and compliance costs in citizen-state interactions. Journal of Public Administration Research and Theory, 25(1), 43-69. doi:10.1093/jopart/muu009

Moynihan, D., Herd, P., \& Rigby, E. (2016). Policymaking by other means: Do states use administrative barriers to limit access to Medicaid? Administration \& Society, 48(4), 497-524.

https://doi.org/10.1177/0095399713503540

Nisar, M.A. (2017). Children of a lesser god: Administrative burden and social equity in citizen-state interactions. Journal of Public Administration Research and Theory, 28(1), 1-16. doi:10.1093/jopart/mux025

Owais, A., Hanif, B., Siddiqui, A. R., Agha, A., \& Zaidi, A. K. (2011). Does improving maternal knowledge of 
vaccines impact infant immunization rates? A community-based randomized-controlled trial in Karachi, Pakistan. BMC Public Health, 11, 239. doi:10.1186/1471-2458-11-239

Reich, J. A. (2020). Vaccine refusal and pharmaceutical acquiescence: Parental control and ambivalence in managing children's health. American Sociological Review, 85(1), 106-127.

Seth, K. 2018. Asking questions: Interviews and expertise in global health research. Medicine Anthropology Theory. doi.org/10.17157/mat.5.5.582

Soss, J., Fording, R., \& Schram, S. F. (2011). The organization of discipline: From performance management to perversity and punishment. Journal of Public Administration Research and Theory, 21, 203-232. https://doi.org/10.1093/jopart/muq095

Streefland, P. H. (1995). Enhancing coverage and sustain ability of vaccination programs: An explanatory framework with social reference to India. Social Science and Medicine, 41(5), 647-56. DOI: 10.1016/02779536(95)00036-7

UNICEF. (2019). Lady Health Worker Programme, Pakistan Performance Evaluation Report. https://www.unicef.org/evaldatabase/files/LHWEvaluation Report.pdf

Van Ryzin, G. G. (2011). Outcomes, process, and trust of civil servants. Journal of Public Administration Research and Theory, 21, 745-60.

https://doi.org/10.1093/jopart/muq092

Varghese, J., Kutty, V. R., Paina, L., \& Adam, T. (2014). Advancing the application of systems thinking in health: Understanding the growing complexity governing immunization services in Kerala, India. Health Research Policy and Systems, 12(47), 1-12. doi: 10.1186/1478-4505- 12-47.
Weaver, R. K. (2014). Compliance regimes and barriers to behavioral change. Governance, 27(2), 243-265. https://doi.org/10.1111/gove.12032

WHO, (2007). Annex 4: Methodology for selection of survey sites by PPS sampling. In, Assessment of iodine deficiency disorders and monitoring their elimina tion. A guide for program managers, third edition. World Health Organisation.

WHO, (2013). Deadly medicines contamination in Pakistan. https://www.who.int/features/2013/pakistan_medicine_safety/en/

WHO, (2015). World Health Organization Vaccination Coverage Cluster Surveys: Reference Manual, Version 3, Working Draft (Updated July 2015).

WHO, (2016). WHO Vaccination Coverage Cluster Survey Reference Manual: What's New? Technical Update. World Health Organisation.

Wolfe, B. \& Scrivner, S. (2005). The devil may be in the details: How the characteristics of SCHIP programs affect take-up. Journal of Policy Analysis and Management, 24, 499-522. https://doi.org/10.1002/pam.20112

Wombwell, E., Fangman, M.T., Yoder, A.K., \& Spero, D.L. (2015). Religious barriers to measles vaccination. Journal of Community Health, 40(3), 597-604. https://doi.org/10.1007/s10900-014-9956-1

Yusufzai, A. (2015). Polio: Arrest warrants for parents reduce cases of vaccination refusal. $D A W N$, March 6 . https://www.dawn.com/news/1167750 


\section{Appendix}

\section{Appendix A. WHO Cluster Survey Method and Fieldwork Reflections}

Our survey was based on the WHO's 30 cluster method. We drew on population data from the 2017 Pakistan census, randomized cluster selection using cumulative population, and then mapped the clusters using Google Maps. We used an older, non-probabilistic version of the WHO's cluster survey method for this pilot survey. Though it would have been more statistically sound to use the updated WHO advice and develop a probabilistic sample for the households surveyed, this was not an option within our time and resource constraints. The sampling frame is included below. Due to our financial and logistical constraints, the survey was not meant to make causal inferences. Instead, it was a pilot intended to inform the design of future surveys and experimental work. For the moment, these plans are on hold due to the COVID-19 pandemic.

The survey was designed to gauge not only why people refuse vaccines, but also to estimate immunization coverage as good, average, or poor in Kasur district. This estimation allowed us to verify the government's data on coverage for the district. The survey was divided into two parts. The first part dealt with household characteristics - how many children under 5 years in the household, income, assets, head of the household's education, and access to facilities such as schools and hospitals. At the end of the first half, the enumerator was prompted to request access to the mother of a child under 5. If there was more than one such child, the enumerator was to sit with each of the mothers and fill out the second half of the questionnaire. The questions for the mothers included their education, pregnancies, use of contraception, understanding of vaccinations, decision making within the family with regard to children's health, trust in government services, and notions of responsibility for children's health. Enumerators were also required to ask for children's vaccination cards and take a photograph of the (anonymized) page with the recorded vaccine doses. Where this card was unavailable, enumerators were to fill out a separate paper form based on mother's recall. We found that $33 \%$ of 179 respondents were unable to locate their child's vaccination card. The survey was conducted using an Android application developed by the Technology for People Initiative at the Lahore University of Management Sciences. Our data is presently embargoed since the project is still underway.

It is important to acknowledge that any household survey is essentially in the hands of its enumerators, as Seth (2018) points out. In topics as sensitive as vaccination in particular, how enumerators translate and put questions to respondents, and the personal baggage they bring to the questions will inform responses. Particularly since vaccination can be a sensitive topic that requires skilled handling, we were not willing to send inexperienced surveyors into the field. We selected enumerators who were familiar with conducting large scale government funded surveys. Their prior experience in the field was invaluable in designing and conducting our survey.

We conducted two days of training with our enumerators to familiarize them with the questionnaire and the Android application, and to guide them on framing questions and handling various responses or queries from respondents. However, even so, in conducting this survey, we continued to be aware of, and reflect on, the challenges of this method of data collection. There were times when respondents did not understand our questions, or where respondents gave detailed answers that could not be captured by a survey form. It was for this reason that we spent considerable time visiting health care facilities and interviewing bureaucrats, frontline health workers, doctors, and members of the communities we visited before, during, and after the survey. The purpose was to triangulate the findings of the survey and to develop a more nuanced, contextualized understanding of immunization programs and health provision in general. 
Our survey team was split into five pairs, each with one woman and one man. The woman enumerator allowed the women of the household to be comfortable discussing their own and their children's health while the man ensured a level of security in knocking on doors. All the men on the enumerator team were from the district of Kasur. This allowed for an additional layer of security since they were not perceived as complete strangers by respondents when they knocked on doors.

In terms of positionality, the co-authors were particularly aware of class signifiers when accompanying the survey team-our clothing and appearance, speaking English, our vehicle, and our survey equipment and materials identified us as outsiders. It was for this reason that the co-authors asked the enumerators to take the lead in the interviews so that respondents would be more comfortable in answering questions.

Enumerator bias was one of our major concerns in conducting this survey. We had to make sure that our enumerators would not be judgmental with respondents over their responses. Neither did we want our enumerators to intimidate respondents, argue with them, or even try to convince them to change their behavior. To some extent, we were successful in ensuring these problems did not arise. However, in some cases of vaccination refusal or missed vaccinations, enumerators did encourage mothers to get their children vaccinated or to at least see a doctor.

Enumerator error was another concern in conducting the survey. Though the enumerators were experienced in conducting surveys, the Android application was still new to them in some respects. As a result, there were some problems, particularly with recording voice responses. Another issue was the phrasing of questions. For instance, the question "Do you know how vaccinations work in a child's body?" did not translate well from English to Urdu or Punjabi, becoming "What are vaccines for?" As a result, some of the responses were confused.

It is also important to discuss our wider experiences in conducting fieldwork for this project, particularly the survey. Vaccination has been a sensitive topic in Pakistan for many years (Martinez-Bravo and Stegman, 2020). Conspiracy theories, misinformation, fake news, doubts, and fears abound. Survey respondents in households in Kasur suspected us of forcing vaccines on them, propagating a practice that they considered made their children sick or even infertile, or collecting data for the government to increase taxes levied on them. In a few cases, our enumerators found themselves being harangued by members of households they visited, and in a couple of cases, found themselves being barred from leaving the house till the respondent was satisfied as to their real motivations. Vaccinators were hesitant in speaking to us, and where they did, they went out of their way to impress upon us that they had vaccinated every single child in their area. On the part of government officials in districts, conversations about immunization are fraught with the pressure to ensure vaccination coverage targets, particularly when there was a sharp increase in polio cases across the country-from 8 in 2017 to 146 in 2019 (Pakistan Polio Eradication Programme - Polio cases by Province https://endpolio.com.pk/polioin-pakistan/polio-cases-in-provinces).

As a result of these realities, a number of people we spoke to were deeply suspicious of our motivations in asking about vaccinations, and our team had to be very careful of our conduct in the field. We spent a considerable amount of time ensuring that the Punjab Department of Primary and Secondary Health and Punjab's Director EPI knew that we were doing this research so as to reduce suspicions amongst health sector bureaucrats. It is important to mention these experiences because two lessons emerge out of them. The first is that studying immunization in Pakistan is a complicated exercise that needs to be handled with care for the safety of all concerned and to ensure that vaccination efforts are not compromised by our intervention. The second is that continued engagement with communities (of citizens and bureaucrats) is essential to build trust and gain access. 


\section{Appendix B. Sampling Frame for Using the WHO 30 Cluster Survey (Non-probabilistic)}

\begin{tabular}{|c|c|c|c|c|}
\hline TEHSIL & $\begin{array}{l}\text { QANOONGO HALQA/MUNICIPAL } \\
\text { COMMITTEE }\end{array}$ & $\begin{array}{l}\text { POPULATION } \\
2017 \text { census }\end{array}$ & $\begin{array}{l}\text { Cumulative } \\
\text { population }\end{array}$ & $\begin{array}{l}\text { Clusters TO- } \\
\text { TAL } 30\end{array}$ \\
\hline \multirow{8}{*}{ Pattoki } & Halla QH & 97554 & 97554 & 1 \\
\hline & Jamber Kalan QH & 130516 & 228070 & 2 \\
\hline & Pattoki I QH & 106706 & 334776 & 3 \\
\hline & Pattoki II QH & 155851 & 490627 & 4 \\
\hline & Pattoki MC & 87737 & 578364 & 5 \\
\hline & Phoolnagar QH & 166746 & 745110 & 6,7 \\
\hline & Phoolnagar TC & 92729 & 837839 & \\
\hline & Sarai Mughal QH & 96490 & 934329 & 8 \\
\hline \multirow{9}{*}{ Chunian } & Allahabad MC & 61933 & 996262 & 9 \\
\hline & Allahabad Theeng Jattan QH & 136058 & 1132320 & 10 \\
\hline & Changa Manga QH & 113257 & 1245577 & 11 \\
\hline & Chunian MC & 72678 & 1318255 & 12 \\
\hline & Chunian I QH & 32379 & 1350634 & \\
\hline & Chunian II QH & 122212 & 1472846 & 13 \\
\hline & Kanganpur MC & 28184 & 1501030 & \\
\hline & Kanganpur QH & 127858 & 1628888 & 14 \\
\hline & Talwandi QH & 131125 & 1760013 & 15 \\
\hline \multirow{12}{*}{ Kasur } & Bhila Hithar QH & 123793 & 1883806 & 16,17 \\
\hline & Ganda Singh Wala QH & 97450 & 1981256 & 18 \\
\hline & Kasur MC & 358409 & 2339665 & $19,20,21$ \\
\hline & Kasur I QH & 124904 & 2464569 & 22 \\
\hline & Kasur II QH & 84366 & 2548935 & \\
\hline & Khadian MC/Khudian MC & 38802 & 2587737 & 23 \\
\hline & Khudian QH & 93479 & 2681216 & \\
\hline & Mustafabad QH & 102057 & 2783273 & 24 \\
\hline & Mustafabad MC & 60654 & 2843927 & 25 \\
\hline & Raja Jang MC & 30876 & 2874803 & \\
\hline & Raja Jang QH & 102784 & 2977587 & 26,27 \\
\hline & Usman wala QH & 117079 & 3094666 & \\
\hline \multirow{5}{*}{ Kot Radha Kishan } & Bhamba I QH & 101802 & 3196468 & 28 \\
\hline & Bhamba II QH & 69951 & 3266419 & 29 \\
\hline & Kot Radha Kishan I QH & 82885 & 3349304 & \\
\hline & Kot Radha Kishan II QH & 46859 & 3396163 & 30 \\
\hline & Kot Radha Kishan MC & 58833 & 3454996 & \\
\hline
\end{tabular}




\section{Appendix C. Responses to Interaction with Vaccinator}

"They ask us how many children we have in the household who have to get [polio] drops, children who are in school get drops there, this one doesn't go to school yet so he gets his drops at home. They tell us the drops are for disease prevention."

"They ask us to bring other women from our neighbourhood who haven't gotten their children vaccinated, they also give details about why the injections are being administered."

"They tell us that the drops protect against polio, and it is the responsibility of the mother to be conscious of this and protect her child from polio."

"It protects against the diseases that come with changing seasons, such as chickenpox and measles, my daughter had chickenpox she got the vaccine now she's better."

"The teams make us understand the need for the vaccines, they are for polio, measles and fever."

"The teams sternly tell us to be careful about getting the vaccines every month, the vaccines are for whooping cough, fever, measles, pneumonia and polio."

"They tell us that the vaccines will protect from measles and polio, we see on television how kids are disabled because of polio and they tell us the same things."

"The vaccines prevent the children from falling sick frequently also protect the child from measles and polio."

"The teams make us understand the need for the vaccines, they are for polio, measles and fever."

"The health worker comes to our home early in the morning when its cooler compared to the day, the vaccines protect against loose motion and fever."

"They say the injections are to ensure good health for your child, the injections include, Penta, OPV, BCG, Hepatitis and Measles."

"They tell us to get the injections administered every time the teams come, also that the injections are for the child's immunity and protection against disease." 


\section{Appendix D: Interview List}

1) Director General Expanded Program for Immunization (EPI) Punjab, 16 October; 20 November 2018

2) Section Officer, Punjab Health Secretariat, 11 December 2018

3) Promotions in-charge, Punjab Health Secretariat, 11 December 2018

4) Vaccinator, Kasur, 13 December 2018

5) District Superintendent Vaccinations, Kasur, 13 December 2018; 17 January 2019

6) Medical officer, Basic Health Unit, Kasur, 13 December 2018

7) Medical Superintendent, Kasur District Headquarter Hospital, 13 December 2018

8) Senior Medical Officer and Medical Officer, Rural Health Centre Kasur, 13 December 2018

9) Trainers (2), Kasur vaccination program, 17 January 2019

10) Medical officers (2), Rural Health Centre, Kasur 9 March 2019

11) Lady Health Visitor, Rural Health Centre, Kasur 9 March 2019

12) Lady Health Worker, Kasur, 18 March 2019

13) Secretary Union Council, Kasur, 20 March 2019

14) Deputy District Health Officer, Kasur, 12 October 2019.

15) Supervising Vaccinator, Kasur, 12 October 2019.

16) Vaccinator, Kasur, 12 October 2019.

17) Lady Health Worker, Kasur, 12 October 2019. 